DOSSIÊ TEMÁTICO: Formação inicial de professores em contextos escolares e binômio teoria/prática nos estágios supervisionados

do1 https://doi.org/10.22481/rpe.v16i43.6828

\title{
ESTÁGIO CURRICULAR SUPERVISIONADO: PERSPECTIVAS DOS LICENCIANDOS DE UM CURSO DE MATEMÁTICA
}

\author{
SUPERVISED CURRICULAR INTERNSHIP: PERSPECTIVES OF GRADUATES
}

\author{
MATHEMATICS STUDENTS
}

\section{PASANTÍA CURRICULAR SUPERVISADA: PERSPECTIVAS DE LOS GRADUANDOS DE UN CURSO DE MATEMÁTICAS}

\author{
Katia Regina da Silva \\ Universidade Federal do Sul e Sudeste do Pará - Brasil \\ Maria Margarete Delaia \\ Universidade Federal do Sul e Sudeste do Pará - Brasil
}

\begin{abstract}
Resumo: O estágio supervisionado é componente obrigatório e indispensável para compor o currículo de formação inicial de professores. Nesse sentido, essa pesquisa objetivou identificar e compreender os principais referentes que evidenciam as percepções dos estagiários, quanto aos processos formativos vivenciados no estágio curricular supervisionado, planejado e executado com o foco na indissociabilidade entre ensino, pesquisa e extensão. $\mathrm{O}$ estágio com esse enfoque é uma proposta desenvolvida pela equipe de professores do curso de licenciatura em matemática de uma Universidade Federal localizada no estado do Pará. Para obtenção dos dados foi realizada uma entrevista semiestruturada com doze estagiários de duas turmas do referido curso e que participaram/participam do projeto. Os dados foram discutidos e interpretados por meio da análise de conteúdo, tendo como principais autores: Tardif(2010), Nóvoa(1991, 2000), Gatti(2014), Pimenta e Lima(2011, 2019), Fiorentini et al(2002), Zimmer(2017), Brancatti(2018) e outros. O estudo permite inferir, principalmente, que: a interação do estagiário no espaço escolar, indispensável ao processo formativo, ultrapassou o limite da sala de aula, ocorrendo com o professor regente, com os alunos, e, também, com os gestores; há uma dificuldade, por parte do estagiário, em fazer a transformação de conteúdos matemáticos aprendidos(ensino) para conteúdos que irão ensinar(aprendizagem), dada a complexidade de alguns, o que requer maior integração e engajamento entre os professores, incluindo aqueles das disciplinas específicas; há um sentimento de protagonismo do estagiário; e percepção da indissociabilidade entre ensino, pesquisa e extensão nas ações, o que contribui para a construção da identidade profissional desde a formação inicial.
\end{abstract}

Palavras-chave: Estágio Curricular Supervisionado. Formação inicial de professores. Indissociabilidade entre ensino, pesquisa e extensão.

Abstract: The supervised internship is a mandatory and indispensable component to compose the initial teacher training curriculum. This research aimed to identify and understand the main referents 
that evidence the perceptions of the interns, regarding the training processes experienced in the supervised curricular internship, planned and executed focusing on the inseparability among teaching, research and extension. The internship is a proposal developed by a group of teachers of the degree course in mathematics of a federal university located in the state of Pará. To obtain the data, a semistructured interview was carried out with twelve interns from two classes of that course who participated / are participating in the project. The data were discussed and interpreted through content analysis, having as main authors: Tardif(2010), Nóvoa(1991, 2000), Gatti(2014), Pimenta e Lima(2011, 2019), Fiorentini et al(2002), Zimmer(2017), Brancatti(2018) and others. The study allows us to infer that: the interaction of the intern in the school space, indispensable to the formative process, crossed the limit of the classroom, occurring with the conducting teacher, with the students, and also with the managers; there is a difficulty, from the intern, in transforming learned mathematical content (teaching) into content that they will teach (learning), given the complexity of some, which requires integration and engagement among teachers, including those from specific disciplines; there is a feeling of protagonism from the intern; and perception of the inseparability among teaching, research and extension in actions, contributing to the construction of professional identity since the initial training.

Keywords: Initial teacher training. Inseparability among teaching, research and extension. Supervised Curricular Internship.

Resumen: La pasantía supervisada es un componente obligatorio e indispensable para componer el plan de estudios de formación inicial del profesorado. En ese sentido, esta investigación tuvo como objetivo identificar y comprender los principales referentes que evidencian las percepciones de los aprendices, en cuanto a los procesos formativos experimentados en la etapa curricular supervisada, planeada y ejecutada con el enfoque en la integración entre enseñanza, investigación y extensión. La pasantía con este enfoque es una propuesta desarrollada por el equipo de profesores del curso de licenciatura en matemáticas de una universidad federal ubicada en el estado de Pará. Para obtención de los datos se realizó una entrevista semiestructurada con doce aprendices de dos clases de dicho curso y que participaron/participan del proyecto. Los datos fueron discutidos e interpretados por medio de análisis de contenido, teniendo como principales autores: Tardif (2010), Nóvoa (1991, 2000), Gatti (2014), Pimenta e Lima (2011, 2019), Fiorentini et al (2002), Zimmer (2017), Brancatti (2018) y otros. El estudio permite deducir, sobre todo, que: la interacción del alumno en el espacio escolar, indispensable para el proceso formativo, superó el límite del aula, ocurriendo con el profesor regente, con los alumnos, y también con los gestores; hay una dificultad, por parte del aprendiz, en la transformación de contenidos matemáticos aprendidos (enseñanza) para contenidos que enseñarán (aprendizaje), dada la complejidad de algunos, lo que requiere una mayor integración y compromiso entre los profesores, incluidos los de las disciplinas específicas; hay un sentimiento de protagonismo del aprendiz; y percepción de la interdependencia entre enseñanza, investigación y extensión en las actividades, lo que contribuye para la construcción de la identidad profesional desde la formación inicial.

Palabras clave: Etapa Curricular Supervisada. Formación inicial de profesores. Interdependencia entre enseñanza, investigación y extensión.

\section{Introdução}

Desde a última atualização do Projeto Pedagógico do curso de Matemática da Faculdade de Matemática, da nossa universidade federal, localizada no estado do Pará, a equipe de professores de estágio, junto aos outros professores do curso, demonstrava 
inquietação com os inúmeros problemas vivenciados em relação à prática de estágio, o que impossibilitava a realização do que está estabelecido no regulamento do curso, principalmente quanto à elaboração e execução de projetos de intervenção, causando distanciamento entre a universidade e a escola. Nós, responsáveis pelo estágio, passamos, então, a concebê-lo e desenvolvê-lo como uma atividade que articula o ensino, a pesquisa e a extensão, ou seja, uma prática que não se limita a observação e regência de aulas dos professores nas escolas. Para isso, assumimos a concepção defendida por Pimenta e Lima (2011, p. 219) de que o estágio deve ser compreendido como um dos componentes curriculares dos cursos de licenciatura "com um campo de conhecimento próprio e um método investigativo que envolve a reflexão e a intervenção na vida das escolas, dos professores, dos alunos e da sociedade na qual estão inseridos". Após termos as primeiras turmas que estão finalizando o estágio elaborado e desenvolvido com base nessa concepção, nos sentimos movidas pela necessidade de reverberar sobre o processo para retroalimentá-lo.

Ancorada nessas premissas, o cerne desta pesquisa voltou-se para o estágio supervisionado no curso de Licenciatura em Matemática, partindo das seguintes questões: Como os estagiários se percebem e avaliam a proposta de estágio voltada para a articulação entre ensino, pesquisa e extensão? Como os estagiários avaliam os processos formativos vivenciados em nossa proposta de estágio? Esse processo tem contribuído para a formação de professores críticos, transformadores e criativos?

Optamos em desenvolver a pesquisa a partir da abordagem qualitativa. Buscamos respaldo em Triviños (1987, p.37), quando pontua que esse tipo de pesquisa não permite visões isoladas, parceladas ou estanques, pois pressupõe interação dinâmica, que se retroalimenta e reformula-se constantemente no decorrer do aprofundamento da temática e imersão no campo de estudo. A investigação a ser desenvolvida nessa perspectiva visa entender as especificidades do objeto e sua relação com a totalidade, considerando as situações na complexidade que lhes são inerentes.

Buscamos a combinação das pesquisas descritiva e explicativa, por acreditar que elas estabelecem uma relação de complementaridade e continuidade entre si. Gil (2002, p. 43) esclarece que a pesquisa explicativa pode ser decorrente de uma pesquisa descritiva à medida que a "identificação de fatores que determinam o fenômeno exige que este esteja suficientemente detalhado".

A coleta de dados da pesquisa ocorreu nos meses de janeiro e fevereiro de 2020, por meio de entrevistas semiestruturadas, contendo questões voltadas para a prática do estágio, 
realizadas com doze alunos do curso de licenciatura em Matemática, ingressantes em 2016 e 2017, que foram as duas primeiras turmas a cursar a disciplina de estágio supervisionado nessa proposta. A análise dos dados considerou os princípios da análise de conteúdo, preconizados por Bardin (2006).

Nesse artigo apresentamos, resumidamente, a proposta de estágio em processo de implementação e as percepções dos primeiros estagiários a vivenciá-la. Acreditamos que o exercício de tornar nosso trabalho como professoras orientadoras objeto de análise suscitou reflexões. O lugar de escuta reflexiva, confrontado ao lugar de fala do professor, coloca-nos em questão, assim como nossas propostas. Desse modo, passamos a repensar nossas ações voltadas à formação do professor de matemática.

\section{A formação inicial de professores em discussão}

Nos desenhos curriculares dos cursos de licenciaturas define-se que no percurso formativo vivenciado no Estágio Curricular Supervisionado, o estagiário aproxime-se e vivencie o cotidiano da escola básica, na busca pela construção de saberes necessários à docência. Entretanto, os modos como são planejados e desenvolvidos os processos formativos do professor nos cursos de licenciatura apresentam configurações e pressupostos, que precisam de reflexões aprofundadas.

Desafiando as abordagens formativas convencionais, pois essas não consideram a identidade do "ser" professor (modos e saberes coletivamente construídos na teoria e na prática) e suas subjetividades, Tardif (2010) coloca a centralidade do processo formativo no protagonismo docente, no sentido de reconhecimento das epistemologias da prática profissional dos professores ${ }^{1}$.

Desse modo, a formação de professores baseada na epistemologia da prática profissional, teria como finalidade:

[...] revelar esses saberes, compreender como são integrados concretamente nas tarefas dos profissionais e como estes os incorporam, produzem, utilizam, aplicam e transformam em função dos limites e dos recursos inerentes às suas atividades de trabalho. Ela também visa a compreender a natureza desses saberes, assim como o papel que desempenham tanto no processo de trabalho docente quanto em relação à identidade profissional dos professores (TARDIF, 2010, p. 256).

1 Tardif define como "epistemologia da prática profissional o estudo do conjunto dos saberes utilizados realmente pelos profissionais em seu espaço de trabalho cotidiano para desempenhar as suas tarefas" (2000, p. 11). 
A articulação de saberes específicos com saberes pedagógicos e empíricos, imersos na realidade do trabalho docente em contexto escolar, possibilita ao professor em processo de formação, construir e fundamentar o "saber-ser" docente.

A experiência acumulada (individual e coletiva), confrontada com as teorias e práticas docentes, constrói a forma de "ser professor" (PIMENTA, 2007). A construção identitária, denominada por Nóvoa (2000, p. 25) de "processo identitário", é coletiva e historicamente construída em processos dinâmicos e complexos nos espaços de conflitos, tradições, teorias, práticas, subjetividades e valores, nos quais o processo de "ser professor" situa os sujeitos no mundo, no ambiente educacional, nas interações com os pares e nas perspectivas de interferência no espaço público e na escola como espaço de transformação social.

Outro aspecto destacado por Nóvoa (2000) refere-se à centralidade da formação de professores para a configuração da profissionalidade docente. Entretanto, alerta Nóvoa (2000), que as formações de professores não estão buscando articular a formação com os "projetos das escolas" e tem ignorado o desenvolvimento pessoal dos professores. Tornando, assim, inviável o desenvolvimento profissional dos professores.

Nóvoa (1991) argumenta em favor de processos de formação, que considerem a dimensão pessoal e profissional como essenciais na produção de sentidos. Para o autor é necessário investir nos saberes dos professores, colocando-os como protagonistas do desenvolvimento profissional e da implementação de políticas educativas em seus contextos de atuação. A escola deve ser o lócus da formação inicial e contínua, espaço do trabalho coletivo e do diálogo.

Destarte, a formação de professores deve ser reconfigurada. Os professores devem participar ativamente no processo de planejamento e implementação de novas políticas educacionais, de repensar a educação e seu próprio papel nesse contexto. Contribuindo para que as instituições escolares se tornem, não apenas espaços de atuação docente, mas também como lócus da formação, propiciando tempo-espaço para estudos coletivos, transformação da práxis pedagógica e desenvolvimento pessoal e profissional no e do coletivo escolar.

\section{Estágio supervisionado: algumas considerações sobre esse processo nos cursos de formação inicial de professores}

Nos cursos da formação inicial de professores, ao longo do percurso histórico, o estágio tem sido objeto de estudo que envolve, e precisa envolver, um amplo diálogo em torno da forma como é pensado e desenvolvido. 
Encontramos na Lei $\mathrm{n}^{\circ} 11.788 / 2008$, no art. $1^{\circ}$, a definição do estágio como sendo um "ato educativo escolar supervisionado, desenvolvido no ambiente de trabalho, que visa à preparação para o trabalho produtivo de educandos que estejam frequentando o ensino regular em instituições de educação superior[...]”. Mas, e nos cursos de licenciatura voltados para a formação de professores, como o estágio está configurado? Como se dá essa "preparação para o trabalho produtivo"?

Durante muito tempo a discussão do estágio nos cursos de licenciatura foi voltada para o modelo da racionalidade técnica. Um modelo que, segundo Silva (2002), priorizava a formação científica em detrimento da formação prática.

Nessa perspectiva, de acordo com Pimenta e Lima (2011, p. 36), o estágio “[...] reduzse a observar os professores em aula e imitar esses modelos, sem proceder a uma análise crítica fundamentada teoricamente e legitimada na realidade social em que o ensino se processa". Ao estagiário cabe a tarefa de simplesmente ir às escolas, adentrar as salas de aula, observar e reproduzir a prática dos professores.

Inseridas nesse contexto, as pesquisas iniciais, focalizando o estágio curricular supervisionado no curso de licenciatura em matemática, segundo Fiorentini et al. (2002), que perpassaram as décadas de 1970 a 1990, visavam, principalmente, avaliar o desempenho do estagiário, sua habilidade prática e a reprodução de modelos preexistentes.

Investigando o papel e as contribuições do estágio curricular supervisionado como espaço formativo do curso de licenciatura em matemática, Fiorentini et al. (2002) também buscaram trazer para a discussão a ressignificação do saber docente e escolar nesse espaço, na tentativa de superar uma concepção de estágio meramente voltado para aplicar teorias e distanciado da experiência prática.

Essa visão reducionista ainda permeia o contexto de formação docente. No entanto, de acordo com Pimenta e Lima (2011), os exemplos clássicos de estágio compostos pela observação, participação e regência de classe e que tem como hipótese que o aprender a ser professor ocorre pela imitação de práticas observadas

[...] revelam seu esgotamento em decorrência da verificação de que essa modalidade não resulta em melhoria dos resultados do ensino, pois a concepção que a sustenta é a de que o ensino é uma atividade técnica que, uma vez aprendida, pode ser aplicada em qualquer situação (PIMENTA; LIMA, 2011, p. 186).

Em uma perspectiva de formação docente mais recente, conforme Gatti (2014), o estágio curricular supervisionado é um espaço no qual teoria e prática, interconectadas aos 
contextos escolares, propiciam a construção de aprendizagens sobre a educação escolar e a docência. Dessa forma, o estagiário pode se envolver, analisar, compreender e propor alternativas para melhorar o processo de ensinar e de aprender, que acontece naquele espaço.

Independente da área de formação a que esteja vinculado, é imprescindível considerar que enquanto componente curricular obrigatório no processo de formação profissional, o estágio “[...] possibilita que sejam trabalhados aspectos indispensáveis à construção da identidade, dos saberes e das posturas específicas ao exercício profissional docente" (PIMENTA; LIMA, 2011, p. 61). Convém frisar que sua prática visa articular a formação pedagógica, a formação específica e a inserção do professor em formação no campo profissional (FERNANDES; SILVEIRA, 2007).

Portanto, ao profissional responsável por orientar e supervisionar o estágio nos espaços de formação e compete, dentre outras funções, de acordo com Leite, Ghedin e Almeida (2008), possibilitar que o estagiário tenha o entendimento de que o trabalho do professor se situa em um determinado espaço e tempo, e que este profissional deve refletir sobre sua prática, como também sobre o contexto político e social que o circunda. Para os autores, o estágio deve buscar formar no estagiário uma visão das diversas dimensões do trabalho docente, e não simplesmente configurar-se pela observação ou práticas com fins em si mesmas.

Conceber e desenvolver o estágio em visão mais ampla, indica entendê-lo como uma atividade que requer olhar para a realidade escolar e, por meio de uma ação investigativa, refletir sobre ele, elaborar propostas de intervenção e voltar com ações que as auxilie, de alguma forma, a melhorar o processo de ensino e de aprendizagem, que já acontece. Isso possibilitará sua realização nos moldes indicados por Pimenta e Lima (2011), em forma de projetos de pesquisa, de interação e de intervenção, como um caminho teórico-metodológico, que melhor possibilite a formação de um professor mais dinâmico, diferenciado no modo de agir e de pensar, por conhecer a realidade do contexto escolar com mais profundidade.

Assim sendo, é possível aprender a ensinar na interação com os outros e com os pares, nas escolas e, principalmente, colocar em prática a indissociabilidade entre o ensino, a pesquisa e a extensão, garantindo a "centralidade da prática por meio de estágios que enfoquem, também, o planejamento, a regência e a avaliação de aula, sob a mentoria de professores ou coordenadores experientes da escola campo do estágio" (BRASIL, 2019, inciso VIII), tal como preconizados pela resolução CNE/CP $n^{\circ}$ 20/2019, que define atualmente as Diretrizes Curriculares Nacionais para a formação inicial de professores para a 
educação básica e institui a Base Nacional Comum para a formação inicial de professores da educação básica.

\section{Proposta formativa de estágio curricular supervisionado: etapas do percurso}

O Estágio Curricular Supervisionado deve contribuir para formação de professores como "[...] profissional crítico-reflexivo e pesquisador de sua práxis e da práxis educativa que realiza na escola em que atua" (PIMENTA; LIMA, 2019, p. 10). Compromissado com as aprendizagens e com a realidade sociocultural de seus alunos, crítico, reflexivo, pesquisador de sua própria prática e com capacidade para melhorá-la cotidianamente.

Assim, em junho de 2018, nós, professoras das disciplinas de Estágio Curricular Supervisionado, começamos a elaborar uma proposta de estágio para nossa faculdade. O formato de Estágio vivenciado até aquele momento se mostrava calcado na reprodução do modelo canônico; restrito quase exclusivamente nas atividades de observação, coparticipação e regência, acompanhadas pelo professor da disciplina de Estágio, quase sem nenhuma participação do professor da classe estagiada; e, com poucas possibilidades de interação, investigação e intervenção no contexto escolar. Incomodamo-nos, ainda mais, quando, em nossas leituras, constatamos que "os estudos sobre os cursos de licenciatura têm evidenciado, [...] que nem sempre coordenadores, professores e alunos percebem esse valor formativo como oportunidade de ir além e de superar uma simples observação, participação e regência na sala de aula." (PIMENTA; LIMA, 2019, p. 10).

Buscando responder a indagação: “[...] até que ponto a escola tem sido um espaço de questionamento, investigação, sistematização e produção de conhecimentos decorrentes da reflexão sobre a sua realidade, sobre si mesma e sobre o ensino que nela se realiza?" (PIMENTA; LIMA, 2019, p. 10) e, refletindo sobre o nosso cenário, envidamos esforços para repensar e elaborar uma proposta de Estágio que, de fato, inter-relacionasse ensino, pesquisa e extensão.

O Projeto Pedagógico do Curso (PPC) do Curso de Matemática de nossa universidade, distribui a carga horária do Estágio em quatro disciplinas de 102 horas cada uma. O estágio inicia-se no quinto período do curso a ser "realizado em escolas de Educação Básica". Os Estágios Curriculares Supervisionados I e II, voltados para Ensino Fundamental e Ensino Médio, respectivamente, preveem a observação, coparticipação e iniciação a regência como atividades inerentes a esse componente curricular, mas devendo privilegiar a pesquisa sobre 
diversos aspectos do campo de atuação na escola básica. Os Estágios Supervisionados III e IV, focados, respectivamente, no Ensino Fundamental e Ensino Médio, “[...] devem voltar-se às atividades de intervenção/extensão, que visa a proporcionar ao futuro professor de matemática observar, analisar e realizar atividades de regência de classe e, ainda, elaborar e executar propostas de intervenção, que podem culminar em atividades de extensão." (UNIFESSPA, 2014, p. 19).

Buscando assegurar o estabelecido no PPC do curso de matemática, além de criar formas de ressignificar as ações desenvolvidas ao longo do Estágio, definimos alguns princípios norteadores das ações desenvolvidas, quais sejam: a integração entre escola e universidade por meio de relação de reciprocidade; o respeito aos saberes provenientes da teoria e da experiência; o reconhecimento e valorização do papel do professor da escola campo como colaborador na formação dos futuros professores; o reconhecimento do aluno como construtor de conhecimento; e a formação de um profissional crítico, reflexivo, pesquisador e interventor de sua própria prática.

A partir de então, coerentes com os princípios estabelecidos, a tríade ensino, pesquisa e extensão, passou a perpassar e integrar todas as ações da proposta de Estágio em andamento na Faculdade de Matemática. A pesquisa, considerada aqui, inerente à ação docente para conhecer e refletir os processos de ensino e aprendizagem dos discentes e docentes em seus contextos escolares; a extensão como ação integradora entre escola e universidade através de intervenções planejadas de acordo com os resultados das pesquisas; e, o ensino dos saberes necessários para os estagiários desenvolverem suas funções nas escolas, para com isso, os estagiários regentes assumirem e se sentirem no papel de professor. Desse modo, o Estágio Curricular Supervisionado, nessa perspectiva, visa favorecer “[...] a compreensão da complexidade da prática/ cultura escolar e suas possibilidades ou alternativas de transformação, requer, por parte dos licenciandos, um trabalho sistemático de reflexão e investigação das práticas cotidianas escolares.” (FIORENTINI, 2008, p. 49).

Em nossa perspectiva formativa, os estagiários, como futuros professores, precisam construir seus saberes pedagógicos e sua identidade profissional através da mobilização e integração dos saberes pedagógicos provenientes das vivências práticas do contexto escolar e de sólida formação teórica.

Para realização de nossa proposta, estabelecemos cinco etapas de ação, interrelacionadas e complementares, a saber: 
a) Primeira etapa: envolve todas as atividades com os estagiários centradas na preparação para as ações nas escolas. Iniciamos o processo de envolvimento dos estagiários no planejamento de todas as ações a serem realizadas nas escolas, desde estudos teóricos a definição de enfoques de pesquisa e elaboração de propostas de intervenções. Os estudos teóricos, nessa fase, focalizam a pesquisa científica, incluindo discussões e estudos sobre instrumentos de pesquisa como entrevistas, questionários e observação participante. Esclarecendo que as situações de reflexões sobre a prática, mediadas por estudos teóricos, ocorrem ao longo e paralelamente a todas as ações do Estágio Curricular Supervisionado, pois concordamos com Fiorentini e Castro (2003, p. 153), que “[...] as atividades de Prática de Ensino e Estágio Supervisionado devem ser acompanhadas e realizadas sob a mediação de leituras/estudos e reflexões ou investigações sistemáticas sobre a prática”.

Formamos duplas de estagiários para elaborarem suas propostas de pesquisa, os orientamos sobre o processo de planejamento das pesquisas a serem realizadas nas escolas, que incluem: critérios e formas de definição de temáticas a serem investigadas; elaboração de problemas e objetivos de pesquisa; elaboração de instrumentos de pesquisa (roteiros de observação e de entrevistas, elaboração de questionários e atividades diagnósticas); seleção e elaboração de base teórica para fundamentar as ações da pesquisa. Promovemos a socialização das propostas de cada dupla para os demais estagiários e para outra turma do curso de matemática que também cursa a disciplina, objetivando criar parcerias entre eles.

b) Segunda etapa: os estagiários são encaminhados para as escolas para realização das ações de pesquisa. Em duplas, desenvolvem atividades em dois dias da semana na escola, com nosso acompanhamento e dos professores regentes. Cada dupla realiza a pesquisa em uma série/ano do ensino fundamental ou médio, dependendo do Estágio que estão cursando. Posteriormente, os estagiários terão compromisso de planejar e desenvolver ações de intervenção a partir dos resultados obtidos nas pesquisas nessas mesmas séries/anos.

c) Terceira etapa: De volta ao espaço acadêmico, orientamos os estagiários a sistematizar e tabular os dados levantados, analisar e discutir os resultados, para produzir um artigo, que integrará o relatório do Estágio. Esse terceiro momento envolve: sistematização; reflexão sobre aspectos práticos e teóricos investigados; e, planejamento das ações de intervenção. As inferências e análises dos resultados indicam as necessidades de aprendizagens, as fragilidades nas metodologias, as defasagens de aprendizagem dos conteúdos matemáticos, entre outros. Com isso é realizado o planejamento das ações de intervenção: regência e oficinas. Nesse momento, entram em cena os professores das 
disciplinas específicas, que tem a responsabilidade de auxiliar os estagiários quanto à transformação dos conteúdos aprendidos nas disciplinas curriculares (de ensino) em conteúdos a serem ensinados na escola (de aprendizagem). A preparação dos estagiários, tanto para as ações para regências, como para as oficinas, é cuidadosamente acompanhada por nós, professores de estágio e pelos professores das disciplinas específicas relativas ao período que os estagiários estão cursando.

d) Quarta etapa: É quando vamos às escolas para realizar as regências de classe e ações de intervenção planejadas. É um momento em que todos os envolvidos, tanto da universidade como da escola, precisam se engajar. A execução das ações de regências e oficinas é acompanhada por nós, pelos professores das disciplinas específicas e professores das escolas campo. Ao longo dessas ações ocorre o processo avaliativo, envolvendo professores regentes, alunos, professores de estágio e de disciplinas do curso de matemática.

e) Quinta etapa: Após executar as ações, é hora de voltar ao espaço universitário para avaliar as ações e preparar o artigo científico com os resultados, que são submetidos a eventos e/ou periódicos internos e externos a universidade. Em seguida, os estagiários reúnem todas as evidências necessárias e elaboram o relatório de estágio, que fica disponível na Faculdade.

Todas as etapas descritas visam contribuir para a ampliação e aprofundamento dos saberes pedagógicos e específicos, apontados por Tardif (2010), além da construção identitária, defendida por Nóvoa (2000), e da práxis educativa docente, discutida por Pimenta e Lima $(2011,2019)$.

\section{Referentes que evidenciam a percepção dos estagiários sobre a proposta do estágio na tríade ensino, pesquisa e extensão}

A entrevista semiestruturada realizada junto aos estagiários foi composta por oito questões, perpassando desde as expectativas iniciais até as aprendizagens adquiridas a partir da vivência no estágio. A seguir, apresentamos os referentes que evidenciam os resultados na percepção dos estagiários:

\section{a) Expectativas antes de iniciar o estágio na escola}

No que concerne a esta questão, os entrevistados se manifestaram de diferentes formas. A Entrevistada $\mathrm{C}$ respondeu que possuía várias curiosidades sobre a docência, mas frisou que esperava "conhecer como seria a realidade da minha futura profissão, como seria o 
convívio com os alunos no ambiente escolar e quais os principais desafios a enfrentar". Ela ressaltou que, no decorrer do Estágio I, suas expectativas foram ampliadas e passou a ansiar pela pesquisa sobre o ensino, a aprendizagem e práticas pedagógicas, que podem ser utilizadas em sala de aula.

Com respostas semelhantes, todos os entrevistados revelaram que tinham curiosidade e preocupação com a maneira com a qual deveriam desenvolver as aulas. O Entrevistado G, inicialmente, afirmou ter expectativas negativas, mas se surpreendeu pelos aprendizados proporcionados pelo estágio. Agora pensa "em até dar aula", indicando maior identificação com a docência.

O Entrevistado F disse que, baseado em conversas com colegas de outros cursos de licenciatura, esperava que “[...] fosse apenas observar as práticas e ações de um professor de matemática em sala de aula e, posteriormente, replicá-las na execução das atividades de estágio". Ainda afirmou que tudo mudou após as primeiras aulas de orientação na universidade e ficou "[...] esperando o momento de ir à escola e aprender a ser um professor, que conseguisse ajudar os alunos a aprender a partir de suas dificuldades". A resposta desse entrevistado indica que o estágio focalizado em alguns cursos de licenciatura ainda prevalece nos moldes da observação e reprodução de modelos da prática, questionados por Pimenta e Lima (2019).

É possível perceber que as expectativas elencadas pelos entrevistados expressam a preocupação do estagiário ao ser inserido no campo, que logo será o seu espaço de trabalho. É um anseio por saber lidar com os acontecimentos da profissão.

Podemos entender que algumas expectativas dos estagiários atrelavam o estágio a “formação preparatória" (CASTRO, 2002, p.30). Embora já apareça preocupações relevantes com as aprendizagens dos alunos e com o papel de professor, não está, nesse momento, presente a expectativa em articular saberes aprendidos na academia com os provenientes da experiência.

b) Experiências relacionadas à equipe gestora da escola, ao professor da disciplina, aos alunos, e às ações da prática docente.

No que tange a relação com a equipe gestora, os entrevistados foram unânimes em registrar que o contato superou a expectativa, pois foram muito bem recebidos e respeitados enquanto estagiários. A Entrevistada $\mathrm{C}$ disse que "a gestão da escola sempre se propõe a escutar as nossas propostas, o que iremos precisar e procura oferecer as melhores condições 
para nós trabalharmos". Os Entrevistados F e K destacaram, que uma contribuição importante da equipe gestora foi para que pudessem descobrir as principais dificuldades dos alunos.

Aos poucos percebemos, que a realização de estágios focalizando o ensino, a pesquisa e a extensão pode ser um caminho teórico-metodológico favorável à mediação entre o processo formativo e a realidade no campo social (PIMENTA; LIMA, 2011). E, acima de tudo, que é uma prática facilitadora para aproximar a escola, a universidade e os interlocutores desses espaços.

Quanto ao professor da disciplina de Matemática, todos os entrevistados fizeram uma avaliação positiva, registrando que no início houve resistência e descontentamento pela presença dos estagiários na escola, mas que isso se reverteu quando passaram a inserir o professor no planejamento e no desenvolvimento das atividades de estágio. A Entrevistada C disse que "no último estágio um professor que, antes de iniciarmos, mostrava-se resistente, no final das nossas ações, se ofereceu para ser nosso parceiro em todas as ações e produções futuras naquela escola". Percebemos que estagiários e professores, nesse diálogo, não aprendem somente "[...] diferentes maneiras de ensinar, como também novas maneiras de enxergar um tema de conhecimento[...]" (STORTI, 2010, p.16), e podem pensar outras/novas formas de ensiná-los.

No que se refere à relação com os alunos, foi unânime o parecer dos entrevistados, estes relataram que o contato permitiu o desenvolvimento da criatividade para adaptação das ações e das metodologias que estavam planejadas. Na visão dos entrevistados “[...] por sermos jovens, os alunos se identificam muito conosco, conseguimos estabelecer uma relação de confiança, que nos possibilita enxergar as dificuldades e tentar saná-las o máximo possível" (Entrevistado F). Isso, de acordo com o Entrevistado E, se justifica porque o foco no estágio não é simplesmente cumprir o planejamento estabelecido desde o início, mas sim criar meios para que o aluno aprenda. Com isso, assinala a Entrevistada K, "vemos realmente os alunos interessados nas ações que desenvolvemos e percebemos que eles aprendem".

É crucial essa percepção dos estagiários de que o processo de ensino e de aprendizagem é, também, construído pelo diálogo e, principalmente, pela confiança dos envolvidos. Há, ainda, o entendimento da necessidade do planejamento prévio das ações, mas que ele é flexível e adaptável as situações para que os objetivos sejam alcançados. É preciso reconhecer que em todo o período do estágio, é fundamental que ocorra momentos de "planejar e replanejar, para que possamos atingir os nossos objetivos, refletir sobre o concreto da realidade escolar e corrigir os desvios do processo" (PIMENTA; LIMA, 2011, p. 224). É 
possível perceber, que sem esse momento torna-se difícil retroalimentar o processo, no intento de melhorá-lo.

Quanto às experiências obtidas por meio das ações da prática docente, encontramos, em todas as respostas dos estagiários, o entendimento da prática docente como uma atividade desafiadora e que, "na prática percebemos que precisamos tentar trabalhar de formas diferentes para alunos diferentes em um mesmo ambiente, o que se torna desafiador" (Entrevistado D). Por isso, destacaram os entrevistados, que é importante essa modalidade de estágio, pois a busca é para trabalhar a partir das dificuldades identificadas. O Entrevistado G ressaltou que as atividades foram importantes para os alunos das escolas campo, pois "eu tenho certeza absoluta que os alunos eram uns antes do estágio [...] depois que passaram por aquela intervenção toda, [...] foram elevados a outro patamar".

Nesse sentido, é importante registrar, de acordo com Brancatti (2018), que o conhecimento e a prática são características indissociáveis e necessários a garantia de uma formação mais consistente.

\section{c) Avaliação dos estagiários quanto a: orientações recebidas para o} desenvolvimento do estágio; contribuições das atividades do estágio para os alunos das escolas campo; e, atuação como estagiário.

Quanto às orientações recebidas para o estágio, em todas as respostas há mostras que se sentiram seguros e confiantes da maneira com a qual as ações foram conduzidas, desde o planejamento até a avaliação final. Para eles, "nunca é somente o planejamento das docentes que é entregue aos estagiários para ser executado, pois vamos discutindo as melhores formas para realizar as atividades e ajustando-as à realidade escolar” (Entrevistada C).

Essa relação entre o professor de estágio e os estagiários é de suma importância para que o processo se desenvolva. Esse também se mostra como um momento de aprendizagem para o estagiário, pois ele começa a perceber que, na relação professor e aluno para a "[...] cooperação ser possível, é preciso, em primeiro lugar, esperar do professor uma posição ética adequada, no sentido de querer que o aluno aprenda e estar aberto a ser questionado, não se colocando na posição de 'detentor de todo saber'” (STORTI, 2010, p. 19). Na prática, é um exercício difícil de ser feito e precisa ser vivenciado no decorrer do processo para ser incorporado como princípio necessário ao ensino e a aprendizagem.

Como contribuições das atividades desenvolvidas na escola para os alunos, todos os entrevistados disseram que o melhor resultado foi conseguir enxergar a aprendizagem, o valor 
que eles passam a dar aos conteúdos matemáticos e o interesse em envolver-se nas ações aplicadas, mesmo quando realizadas no contraturno. Esse retorno, dado pelos alunos na escola campo, é fundamental para que o estagiário se mantenha atento e instigado a produzir e buscar o reflexo do que ensina nas manifestações de aprendizagens, procurando outras/novas formas de dar continuidade ao processo de ensino.

No que concerne à atuação enquanto estagiário, alguns revelaram ansiedade inicial e, ao final, disseram que foram compensados pelo aprendizado da experiência e superação dos medos iniciais. Todas as respostas indicaram que os estagiários buscaram se envolver com as ações e se preocuparam com o planejamento e o domínio de conteúdos. Ressaltaram que, nessa modalidade de estágio, é preciso se preparar muito mais para terem condições de interagir e auxiliar os alunos. Há uma percepção de que possuem lacunas a serem melhoradas e que não podem descuidar do estudo mais aprofundado acerca do que irão ensinar. Para que isso ocorra, "[...] o diagnóstico da escola se torna base importante para o desenvolvimento do estágio". (PIMENTA; LIMA, 2011, p. 224).

Nesse processo, é possível perceber a evolução dos alunos quanto ao cuidado para com o ensino e com a aprendizagem. Eles começam a enxergar a complexidade e amplitude presente no processo educativo, e, principalmente, que “[...] a habilidade que o professor deve desenvolver é saber lançar mão, adequadamente, das técnicas conforme as diversas e diferentes situações em que o ensino ocorre, o que necessariamente implica a criação de novas técnicas" (PIMENTA; LIMA, 2011, p. 38-39). Torna-se necessário enfatizar a importância do domínio dos conteúdos a serem ensinados cotidianamente. Percebemos que esse é um momento onde o estagiário inicia o processo de maturidade profissional e começa a incorporar elementos, que farão parte de sua futura vida como docente. É como Nóvoa (2000) nos conduz a refletir, que o processo identitário precisa ser vivenciado em todo o percurso formativo.

\section{d) Importância do estágio enquanto componente curricular para os cursos de}

\section{formação de professores}

Os entrevistados, por unanimidade, disseram que veem o estágio como essencial para a formação, considerando que o curso que fazem é de licenciatura e precisam ter contato com ações da profissão. Destacaram que o estágio possibilita a experiência prática em turmas do ensino fundamental e médio, vivenciando desafios do contato com o gestor da escola, com o professor da disciplina e com os alunos. É um momento no qual veem a possibilidade de, 
diante dos desafios da futura profissão, "ver e pensar em novas metodologias para ensinar os conteúdos dessa disciplina, que é tão temida por muitos alunos” (Entrevistado D).

Os entrevistados defenderam que, o estágio é indispensável para que o licenciando tenha experiência e saiba se realmente é isso que ele quer enquanto profissão. É nesse momento que "vamos ter contato com a vida real: escola, sua estrutura, professores e alunos" (Entrevistada K). Para o Entrevistado J “[...] é o primeiro momento que a gente tem contato com a docência e é onde a gente vai começar a aprender, começar a colocar em prática as teorias que vemos nos livros e na sala de aula." Os estagiários demonstraram, dessa forma, a transição inicial para o papel de professor estagiário (CASTRO, 2002). Momento onde passam a se aproximar da condição de professor.

Esse procedimento seria fundamental na constituição de sua identidade profissional, pois deixava de se ver apenas como aluno-estagiário e passava, gradativamente, a assumir uma postura de professor que reflete sobre aquilo que faz e discute sobre o que e como ensinar. (CASTRO, 2002, p. 85)

Vale destacar aqui que, aos poucos, a resistência e negativa pelas disciplinas pedagógicas, comuns nos cursos de licenciatura, por parte de alunos e professores, onde prevalece, ainda, uma tradição bacharelesca, tal como sinalizado por Zimmer (2017), vai dando lugar ao reconhecimento da necessidade dos conhecimentos pedagógicos para articular os conteúdos estudados, buscando formas para serem ensinados.

e) Se durante o estágio conseguiu transformar os conteúdos aprendidos no curso de licenciatura em conteúdos a serem ensinados para os alunos da escola campo

Nessa questão, todos os entrevistados não esconderam que sentiram muita dificuldade em fazerem essa transformação de conteúdos que aprendem, para conteúdos que serão ensinados, porque, segundo eles, ao estudarem os conteúdos na graduação, o fazem de uma forma mais complexa e mais profunda. Para eles esse é um grande desafio, pois "para o aluno precisamos fazer relações menos complexas, mais palpáveis e mais passíveis de entendimento. É preciso descomplicar um assunto para ser ensinado" (Entrevistado E). Nesse sentido, frisaram que a parceria entre a professora de estágio e os professores das disciplinas específicas tem sido essencial, pois "nos é oportunizado que seja realizada revisão dos conteúdos das disciplinas básicas e transformação desses conteúdos para irmos à escola. Para nós, é um grande momento de aprendizagem” (Entrevistada C). 
O deslocamento exigido, deixar o pensamento matemático complexo desenvolvido na academia, para assumir o pensamento matemático definido como conteúdo matemático a ser aprendido na escola básica, coloca o estagiário em conflito com seu próprio processo de aprendizagem. Por isso, é imprescindível a participação do professor das disciplinas específicas junto às ações do estágio, a fim de auxiliar os estagiários a fazerem essa articulação, pois a matemática escolarizada é,

[...] um saber construído pelos educadores matemáticos mediante um processo de interlocução entre a matemática científica e a matemática produzida/mobilizada nas diferentes práticas cotidianas, sendo uma dessas práticas cotidianas aquela que acontece nas escolas (FIORENTINI, 2008, P. 53)

Entendemos que ter o professor das disciplinas específicas colaborando para a realização do estágio, é indispensável para ocorrer o planejamento e a execução de ações, que contribuam para a melhoria das dificuldades detectadas por meio das pesquisas desenvolvidas. Como preconiza a resolução CNE/CP n 20/2019, deve haver o "engajamento de toda a equipe docente do curso no planejamento e no acompanhamento das atividades de estágio obrigatório" (BRASIL, 2019, inciso X). Mas, o que vemos, na prática, ainda é pouco ou quase nenhum envolvimento dos professores em ações conjuntas. Pimenta e Lima (2011, p. 33) registram que

[...] os currículos de formação têm-se constituído em um aglomerado de disciplinas isoladas entre si, sem qualquer explicitação de seus nexos com a realidade que lhes deu origem. Assim, nem sequer se pode denominá-las teorias, pois são apenas saberes disciplinares em cursos de formação, que em geral estão completamente desvinculados do campo de atuação profissional dos futuros formandos.

O estágio é preciso ser entendido como "espaço de projetos interdisciplinares, ampliando a compreensão e o conhecimento da realidade profissional de ensinar" (PIMENTA; LIMA, 2011, p. 17). É possível que a partir do momento que essas ações se tornarem parte do processo formativo ocorra a ampliação do estudo, das análises e das problematizações dos conhecimentos a serem construídos no processo formativo docente.

\section{f) Percepção da relação entre ensino, pesquisa e extensão}

Todos os estagiários disseram que perceberam e vivenciaram a indissociabilidade entre ensino, pesquisa e extensão nas ações do estágio. A Entrevistada C resumiu da seguinte forma: 
Em um primeiro momento do estágio, ocorre o ensino quando recebemos todas as orientações e nos preparamos para ir às escolas. Vejo a pesquisa quando elaboramos e aplicamos questionários, entrevistas, observações e atividade para diagnosticar as dificuldades dos alunos em relação aos conteúdos, bem como, quando fazemos a tabulação e análise dos dados obtidos [...]. Há o ensino e a pesquisa juntos quando buscamos referenciais teóricos, que nos possibilitam analisar os dados coletados. Ainda temos ensino quando estudamos e planejamos as ações [...], usando recursos do Laboratório de Ensino de Matemática e outros meios. Temos a extensão quando executamos, nas escolas, tudo o que planejamos.

Podemos inferir que os estagiários entrevistados compreendem o ensino, pesquisa e extensão, como indissociáveis e inter-relacionados, sem ênfase de um em detrimento de outro. São articulados e necessários para que o processo tenha êxito. Dessa forma, é possível que compreendam que a universidade que "[...] tem por intencionalidade a formação integral do discente, a partir da indissociabilidade entre ensino, pesquisa e extensão, precisa prezar pela cultura de construção e compartilhamento de conhecimento" (ALMEIDA, 2018, p. 198). E, ainda, que educar, de acordo com Zabala, significa “[...] formar cidadãos e cidadãs, que não estão parcelados em compartimentos estanques, em capacidades isoladas” (1998, p. 28), por isso, essa integração e indissocialização é necessária.

\section{g) Influência do estágio na opção pela docência}

Dentre os entrevistados, a maioria afirmou que o estágio reforçou a sua opção pela docência. Para a Entrevistada C, com a vivência e os desafios do estágio, "reafirmo que quero ser professora de Matemática, porém, quero atuar na escola pública, pois vi que os alunos têm muitas dificuldades e chegam a odiá-la, sendo que podemos mostrá-la no cotidiano e ensinar a partir disso". Os entrevistados G e F afirmaram que não pretendiam ser professores. Segundo G “[...] a partir do estágio eu comecei a mudar minha visão, [...] eu já admito a possibilidade de ser um professor". Ainda nesse sentido, o Entrevistado F disse que sonha ser engenheiro, mas com o estágio "uma parte de mim já quer seguir a carreira docente”.

É possível, por meio dessa prática do estágio, que o estagiário se perceba como professor à medida que desenvolva as ações em sala de aula. É importante ressaltar que

Realizar os estágios nessa perspectiva supõe, pois, o compromisso de realizar projetos significativos para uma escola de melhor qualidade, voltada à inclusão social e em constante diálogo entre os participantes. Somente acreditando que as pessoas, juntas, têm a capacidade de transformar a realidade é que o projeto pode deixar de ser um instrumento burocrático para ser um instrumento de ensino e de aprendizagem tanto do aluno como do professor. À medida que as pessoas se sentem coautoras e não apenas 
executoras, estão assumindo melhor o projeto e suas consequências. (PIMENTA; LIMA, 2011, p. 220-221).

E ainda, de acordo com a autora, apesar de inúmeras vezes influenciarmos, mesmo sem intencionalidade, a aprendizagem de nossos alunos quando nos observam e imitam o que fazemos enquanto docentes, eles acabam fazendo suas próprias elaborações a partir da negativa daquilo que não veem como positivo em nossas práticas e ações. Nesse processo acabam escolhendo, separando o que julgam ser mais adequado, somam a isso outras formas de ser e fazer, adaptando-se aos diferentes contextos no qual estão inseridos. Para isso, lançam mão de suas experiências e dos saberes que adquiriram no decorrer do processo. Esse é um momento importante que vai, aos poucos, contribuindo para a construção de sua própria identidade profissional.

\section{h) Aprendizagens adquiridas por meio do estágio}

Os entrevistados fizeram a retrospectiva das ações desenvolvidas e enumeraram aprendizagens adquiridas no processo. Os Entrevistados $\mathrm{C}$ e $\mathrm{H}$ disseram que tiveram conhecimento de como vai ser a sua futura profissão, bem como os possíveis desafios e alegrias que encontrarão. A Entrevistada $\mathrm{C}$ afirmou que "por meio da articulação entre ensino, pesquisa e extensão, no estágio, aprendemos e desenvolvemos resumos, artigos científicos, participamos de eventos". O Entrevistado D acrescentou que "em sala de aula não dá para tratar todos os alunos como iguais, por isso precisamos pesquisar, identificar e analisar as diferenças e ajudá-los".

Abordando aspectos metodológicos, o Entrevistado E ressaltou ter percebido que "o professor precisa partir das dificuldades dos alunos e saber mediar quando é que ele tem que ir para o quadro e fazer uma aula expositiva, de quando ele vai precisar utilizar recursos para facilitar o entendimento". Em concordância, para os Entrevistado K e F, o estágio o levou a querer "ensinar a matemática de uma maneira divertida e com significado para a vida dos alunos". Por fim, o Entrevistado B afirmou que o processo educacional vai além de "transmitir conteúdos".

É possível perceber, que os estagiários começam a entender que o processo de ensino se relaciona a integração adequada entre saberes dos conteúdos matemáticos e saberes didático-pedagógicos. Como defende Fiorentini (2008, p. 50-51), esse processo

[..] configura-se no principal eixo da formação dos saberes da docência, pois interliga, de forma intencional e problematizadora, o saber matemático que é objeto de ensino-aprendizagem e os saberes didático-pedagógicos e 
curriculares, incluindo aí também o sentido educativo/formativo subjacente à prática escolar que acontece ao ensinar e aprender esses conteúdos.

É importante registrar a percepção de como o estágio discorrido nessa perspectiva pode possibilitar o desenvolvimento de atitudes e habilidades que poderá leva-lo a enxergar e almejar um melhor desempenho profissional. Eles conseguem realizar a empatia e, por meio dela, fazer projeções profissionais diferentes daquelas que presenciaram nas escolas enquanto estagiavam.

\section{i) Considerações espontâneas dos entrevistados}

Os entrevistados destacaram a importância que esse tipo de estágio tem para a vida acadêmica, enquanto graduandos de licenciatura, e profissional, enquanto futuros professores de matemática. Todos falaram que queriam ficar mais tempo na escola e reconheceram a necessidade de desmistificar a forma como a matemática é trabalhada pelos professores. A Entrevistada $\mathrm{C}$ afirmou que há “protagonismo em todo o processo, pois são os próprios estagiários, junto com o professor de estágio, que planejam e desenvolvem as ações desde o ensino, perpassando pela pesquisa e culminando na extensão. Tudo é decidido em conjunto".

Sentir-se protagonista do processo é um marco significativo para a continuidade do projeto de estágio, que articula ensino, pesquisa e extensão, numa perspectiva de formação profissional docente. Salientamos que a construção da identidade do professor se dá ao longo do seu percurso profissional na carreira, como indica Nóvoa (1991). E dessa forma, os estagiários vão se conscientizando que "é no processo de sua formação que são consolidadas as opções e intenções da profissão que o curso se propõe legitimar" (PIMENTA; LIMA, 2011, p. 62). Essa postura permite a ação do estagiário como sujeito do processo e não mero executor, o que pode tornar possível e viável os planejamentos, implementações e consolidações de outras/novas ações profissionais futuras.

\section{Considerações finais}

Considerando a experiência, na perspectiva de Bondia (2002, p. 20), como sendo o "que nos passa, o que nos acontece, o que nos toca", podemos afirmar que nossos estagiários tiveram experiências verdadeiras ao longo das ações do estágio.

Ao investigarmos como os estagiários percebem e avaliam a proposta de estágio concebido na articulação entre ensino, pesquisa e extensão, podemos vislumbrar que nossos objetivos estão sendo alcançados. Principalmente no propósito de aproximação e maior 
interação entre a academia e o ensino básico público, como vimos nos resultados da pesquisa e na inserção dos estagiários no processo reflexivo sobre a prática docente.

As falas dos entrevistados indicam que as expectativas dos estagiários sobre as ações do estágio, envolviam apreensão pelo que desconheciam e ao mesmo tempo curiosidade em descortinar e adentrar nessa realidade. Além disso, tinham expectativas mais identificadas com a racionalidade técnica: a prática pedagógica como técnicas de ensinar. Mais distantes da perspectiva de compreender a prática pedagógica como práxis, e não como técnica.

Sobre as experiências relacionadas à equipe das escolas campo, aos professores regentes, aos alunos da educação básica e ações da prática docente, os entrevistados avaliaram de forma positiva. Para eles, as interações estabelecidas no espaço escolar, indispensáveis ao processo formativo, ultrapassaram o limite da sala de aula, sendo estabelecida com o professor regente, com os alunos, e, também, com a equipe gestora da escola.

As avaliações dos estagiários sobre suas percepções das orientações recebidas para o estágio; das contribuições das atividades do estágio para os alunos das escolas campo; e, atuação como estagiário, indicaram aprovação por parte deles em relação a todos esses aspectos. Essa aprovação pode resultar do envolvimento dos estagiários em todas as etapas do desenvolvimento das ações do estágio, desde os estudos teóricos, a pesquisa, até as ações de intervenção. Eles passaram a se sentir mais engajados e comprometidos com as ações do estágio, como "protagonistas".

Os entrevistados foram unânimes no reconhecimento do estágio como fundamental para a formação, bem como uma importante experiência prática com a docência e com a vida escolar.

Quanto a fazer a transformação de conteúdos matemáticos aprendidos para conteúdos a serem ensinados, foi evidenciada a dificuldade dos estagiários em realizar esse processo. Essa questão, segundo Fiorentini (2008), é complexa porque o conteúdo matemático escolarizado resulta do amálgama entre matemática científica e matemática das práticas cotidianas, inclusive das que ocorrem na escola. Desse modo, dada essa complexidade, a integração e engajamento entre os professores de estágio e professores das disciplinas específicas do curso de matemática precisam ser ampliadas.

Outro aspecto relevante para o estudo trata da percepção sobre a indissociabilidade entre ensino, pesquisa e extensão nas ações do estágio, revelada pelos entrevistados. Eles reconheceram a integração nas ações e atividades que desenvolveram no estágio e perceberam que são indissociáveis nesse percurso. 
Quanto à influência na opção pela docência, as respostas demonstram que o estágio contribui para a construção da identidade profissional desde a formação inicial. A maioria afirmou que o estágio reforçou a sua opção pela docência.

Instados a fazerem considerações do que quisessem acrescentar, os entrevistados retornam ao valor da experiência (BONDIA, 2002), quando revelam o sentimento de protagonismo do estagiário. Evidenciam, assim, que o estágio não pode ser burocrático, limitado a observação, regência e coparticipação. Ele deve ser um processo imersivo na vida da escola, em parceria com seus atores.

Por fim, nossas análises possibilitam algumas conclusões. Em primeiro lugar, entendemos que os estagiários assimilaram a proposta de estágio que está sendo implementada. Começaram a compreender que o estágio tem compromisso com a formação docente, mais especificamente, com a vivência e análise da práxis docente. Desse modo, ele deve se constituir como lugar de reflexão, discussão, pesquisa, intervenção, sobre as diversas questões que envolvem a prática pedagógica e o contexto escolar.

Em segundo, os resultados indicam que é possível conceber e realizar um trabalho de estágio, no qual os movimentos dialéticos prática/teoria e ensino/pesquisa/extensão se imbricam e se concretizam de forma construtiva e interativa. Esse sentido foi possível devido ao envolvimento ativo dos estagiários, professoras de estágios e de disciplinas específicas, professores regentes e equipe das escolas campo. Estes apontamentos parciais parecem corroborar com as conclusões teóricas de que é possível práticas educadoras transformadoras (e de estágios supervisionados), onde se possibilita a ampliação e aprofundamento dos saberes pedagógicos e específicos, para a construção da práxis educativa docente (PIMENTA; LIMA, 2011, 2019).

\section{REFERÊNCIAS}

ALMEIDA, A. L. de. A gestão do conhecimento como ferramenta aplicada à indissociabilidade do ensino, pesquisa e extensão universitária. 2018. Dissertação (mestrado) - Faculdade de Filosofia e Ciências, Universidade Estadual Paulista "Júlio de Mesquita Filho", Marília, 2018. Disponível em: http://hdl.handle.net/11449/154277. Acesso em: 10 nov. 2019.

BARDIN, L. Análise de conteúdo. São Paulo: Persona, 2006.

BONDIA, Jorge Larrosa. Notas sobre a experiência e o saber de experiência. Rev. Bras.

Educ., Rio de Janeiro, n. 19, p. 20-28, Apr. 2002 . Disponível em: 
<http://www.scielo.br/scielo.php?script=sci_arttext\&pid=S1413-

$24782002000100003 \& \operatorname{lng}=\mathrm{en} \& n r m=\mathrm{iso}>$. Acesso em 27 Mar. 2020.

BRANCATTI, P. R. Trajetórias de formação construídas a partir dos projetos de

extensão universitária: o olhar dos egressos do curso de Licenciatura em Educação Física da FCT/UNESP. Tese (doutorado) - Faculdade de Ciências e Tecnologia, Universidade Estadual Paulista "Júlio de Mesquita Filho", Presidente Prudente, 2018. Disponível em:

https://repositorio.unesp.br/bitstream/handle/11449/180202/brancatti_pr_dr_prud.pdf?sequen ce $=3 \&$ isAllowed $=y$. Acesso em: 09 nov. 2019.

BRASIL. Lei $\mathbf{n}^{0}$ 11.788, de 25 de setembro de 2008. Dispõe sobre o estágio de estudantes[...] e dá outras providências. Disponível em: https://proeg.unifesspa.edu.br/images/conteudo/proeg/LEI11788.pdf. Acesso em: 08 jan. 2019.

BRASIL. Resolução CNE/CP no 2, de 20 de dezembro de 2019. Define as Diretrizes Curriculares Nacionais para a Formação Inicial de Professores [...] e dá outras providências. Disponível em: http://portal.mec.gov.br/docman/dezembro-2019-pdf/135951-rcp002-19/file. Acesso em: 08 fev. 2020.

CASTRO, F. C. de. Aprendendo a ser professor(a) na prática: estudo de uma experiência em prática de ensino de matemática e estagio supervisionado. 2002. 149 p. Dissertação (mestrado) - Universidade Estadual de Campinas, Faculdade de Educação, Campinas, SP. Disponível em: <http://www.repositorio.unicamp.br/handle/REPOSIP/253694>. Acesso em: 20 de fev. 2020.

FERNANDES, C. M. B.; SILVEIRA, D. N. da. Formação inicial de professores: desafios do estágio curricular supervisionado e territorialidades na licenciatura. In: $30^{\mathrm{a}}$ Reunião Anual da ANPED. Anais... Caxambu- MG, 2007. p. 1-12.

FIORENTINI, D. A Pesquisa e as Práticas de Formação de Professores de Matemática em face das Políticas Públicas no Brasil. Boletim de Educação Matemática, vol. 21, no. 29, 2008, pp.43-70. Redalyc. Disponível

em: https://www.redalyc.org/articulo.oa?id=291221870004. Acesso em: 20 mar. 2020.

FIORENTINI, D.; NACARATO, A. M.; FERREIRA, A.C.; LOPES, C. S.; FREITAS, M. T. M.; MISKULIN, R. G. S. Formação de professores que ensinam matemática: um balanço de 25 anos da pesquisa brasileira. Revista em Educação, Belo Horizonte, n. 36, p. 137-160, 2002. Disponível em: https://www.repositorio.ufop.br/bitstream/123456789/1098/1/ARTIGO_Forma\%c3\%a7\%c3 \%a3oProfessoresEnsinam.pdf. Acesso em: 08 fev. 2020.

; CASTRO, F. C. Tornando-se professor de matemática: o caso de Allan em prática de ensino e estágio supervisionado. In: FIORENTINI, D. (Org.) Formação de professores de matemática: explorando novos caminhos com outros olhares. Campinas: Mercado de Letras, 2003.

GATTI, B. A. Formação inicial de professores para a educação básica: pesquisas e política educacionais. Est. Aval. Educ., São Paulo, v. 25, n. 57, p. 24-54, 2014. Disponível em: http://www.fcc.org.br/pesquisa/publicacoes/eae/arquivos/1899/1899.pdf. Acesso em: 08 fev. 2020. 
GIL, A.C. Como elaborar projetos de pesquisa. 4. ed. São Paulo: Atlas, 2002.

LEITE, Y. U. F.; GHEDIN, E.; ALMEIDA, M. I. Formação de professores: caminhos e descaminhos da prática. Brasília: Líber Livro Editora, 2008.

NÓVOA, A. (org.). Vidas de professores. Porto: Porto Editora, 2000.

. O processo histórico de profissionalização do professorado. In: Nóvoa, A (org).

Profissão Professor. Porto: Porto Editora, 1991.

PIMENTA, S. G.; LIMA, M. S. L.. Estágio e docência. 6. ed. São Paulo: Cortez, 2011. (Coleção Docência em Formação. Série Saberes Pedagógicos).

. Estágios supervisionados e o Programa Institucional de Bolsa de Iniciação à

Docência: duas faces da mesma moeda? Revista Brasileira de Educação, v. 24 e 240001, 2019. Disponível em: Revista Brasileira de Educação v. 24 e 240001 2019. Acesso em: 20 mar. 2020.

PIMENTA, S. G . Saberes docentes e atividade docente. 5. ed. São Paulo: Cortez, 2007.

SILVA, C. M. S. Formação de professores e pesquisadores de matemática na Faculdade Nacional de Filosofia. Cadernos de pesquisa, n. 117, p. 103-126, 2002.

STORTI, T. P. O ensino individualizado: a educação matemática na relação aluno-professor. 2010. 189f. Dissertação (Mestrado em Educação) - Faculdade de Educação, Universidade de São Paulo, São Paulo, 2010. Disponível em:

https://teses.usp.br/teses/disponiveis/48/48134/tde-16122010-100722/en.php. Acesso em: 12 nov. 2019.

TARDIF, M.. Saberes docentes e formação profissional. 11. ed. Petrópolis, RJ: Vozes, 2010.

TRIVIÑOS, A. N. S. Introdução à pesquisa em Ciências Sociais: a pesquisa qualitativa em educação. São Paulo: Atlas, 1987.

UNIFESSPA. Projetos Pedagógico Matemática (PPC) 2014. Disponível em:

https://famat.unifesspa.edu.br/images/Legislacao-

Academica/PPC_Matematica_anexos_e_resolucao.pdf. Acesso em: 03 mar. 2020.

ZABALA, A. A prática educativa: como ensinar. Porto Alegre: Artmed, 1998.

ZIMMER, I. Estágio curricular supervisionado na licenciatura em Matemática: um componente curricular em discussão. 2017. 220 f. Tese (Doutorado em Educação Matemática) - Pontifícia Universidade Católica de São Paulo (PUC-SP), São Paulo, 2017 Disponível em:

https://repositorio.ufsc.br/xmlui/bitstream/handle/123456789/179888/350643.pdf?sequence=1 \&isAllowed=y. Acesso em: 08 fev. 2019. 


\section{SOBRE AS AUTORAS:}

\section{Maria Margarete Delaia}

Graduada em Pedagogia (Licenciatura), Habilitação Supervisão Escolar. Especialista em Metodologia de Ensino Superior, pela PUC-Minas e Planejamento Educacional, pela Universo - RJ. Mestre em Ciências da Educação, pelo Instituto Superior Pedagógico Enrique José Varona - Cuba. Doutora em Educação, pela Universidade Federal de Pelotas (PPGE/FaE/UFPel). Líder do grupo de pesquisa: Estágio Supervisionado: articulação entre ensino, pesquisa e extensão. É docente, com dedicação exclusiva, na UNIFESSPA - Campus de Marabá, no Curso de Matemática, licenciatura (FAMAT/ICE). E-mail: margareteds@gmail.com

\section{(iD http://orcid.org/0000-0002-1179-4948}

\section{Katia Regina da Silva}

Possui graduação em Pedagogia pela Universidade Federal do Pará (1999), mestrado em Educação pela Universidade Católica de Brasília (2007) e doutorado em Educação pela Universidade Federal de Minas Gerais (2018). Atualmente é professora da Universidade Federal do Sul e Sudeste do Pará (UNIFESSPA). E-mail: katia@ unifesspa.edu.br (iD http://orcid.org/0000-0002-8132-284X 